\title{
DC Capacitor Voltage Balaneing Control for Chain STATCOM
}

\author{
Li Shengqing, Tang Qi, Bai Jianxiang, Yuan Li \\ College of Electrical and Information Engineering \\ Hunan University of Technology \\ Zhuzhou, China \\ e-mail:1sq1961@ @ohu.com
}

\begin{abstract}
Abstrack-Because the chain STATCOM each inverter bridge DC side are independent of each other, the DC side voltage is difficult to balance, how to make the voltage of each inverter DC capacitor is consistent, safe and stable operation of the key device.For chain STATCOM DC capacitor voltage balancing problem, create a mathematical model of the single-phase equivalent chain STATCOM in hierarchical control architecture based on the proposed balanced adjacent inductance energy to control its various modules DC capacitor voltage balance. Before the upper realized by feedforward decoupling control system of total active and reactive power control; lower using the proposed control method, in order to control the DC voltage inductor size as an intermediate storage unit transfer high voltage DC capacitor energy; finally, to out of the adjacent inductance balanced energy control specific method. Simulation and experimental results show that this method can effectively stabilize the chain STATCOM DC capacitor voltage, high precision, speed, control methods and simple.
\end{abstract}

Keywords-chain STATCOM; DC capacitor voltage balance; feedforward decoupling control; inductive energy balance adjacent; hierarchical control

\section{INTRODUCTION}

Chain STATCOM has no need of multiple access transformer,small occupation area,convenient modularized, flexible control and operation range and other advantages, has become the development direction of modern reactive power compensation device. In the chain of STATCOM, because the DC side capacitor are independent of each other, the DC side capacitor voltage imbalance will cause the harmonic distortion of the output voltage of STATCOM increases the rate of chain, serious will endanger the safe reliable operation of the equipment, the DC voltage balance control becomes the key problem of cascade STATCOM. The literature of [1] by digital simulation and physical model test are compared with each other, studied the effects of various factors on the capacitor voltage assignment, it points out that the hybrid shunt loss differences, differences and different input pulse delay is a major cause of capacitor voltage unbalance. Aiming at the problem of DC side capacitor voltage balance, reference $[2,3]$ is proposed to achieve DC voltage balance control through the external energy exchange, this method can simplify the control algorithm program, reduce control difficulty. The literature [4] based on hierarchical control, realize the voltage balance through active power voltage vector superposition method, the good control characteristics, parameter design is simple, the DC capacitor voltage consistent good. The literature [5, 6] through the phase change of each unit of angle of the inverter to achieve voltage balancing, but for large capacity inverter, the phase shift angle adjustable range is small, change the phase angle is easy to cause system instability. Literature [7] presented an independent voltage balancing strategy to achieve voltage balancing, sine the methods need to be divided by the current value of the phase, but the sine value zero value is too small, the system is more sensitive to perturbations becomes.

In this paper through the adjacent inductance balanced energy to control the chain STATCOM DC side capacitor voltage balance, by the inductance as intermediate storage unit, will transfer the DC side capacitor voltage high capacitance energy to adjacent voltage is low, the realization of DC voltage balance, has the advantages of high precision, fast speed, simple control method ect.

\section{CHAIN STATCOM MATHEMATICAL MODEL}

The chain structure of STATCOM system as shown in Fig .1, the link from $\mathrm{N} \mathrm{H}$ bridge inverter (module A) composition, system voltage respectively usa usb、usc, equivalent resistance is $\mathrm{R}$, connected reactance is $\mathrm{L}$, the chain of STATCOM output voltage respectively uca、 ucb 、 ucc, the compensation current ica icb 、icc.

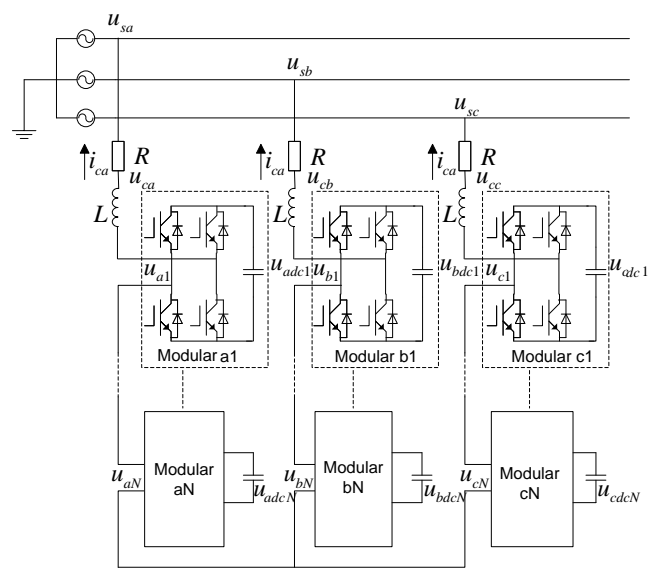

- $\quad$ Figure 1 Chain STATCOM system architecture

Fig .1(b), can get the chain STATCOM mathematical expressions 


$$
\left\{\begin{array}{l}
R i_{c a}+L \frac{d i_{c a}}{d t}+u_{c a}=u_{s a} \\
R i_{c b}+L \frac{d i_{c b}}{d t}+u_{c b}=u_{s b} \\
R i_{c c}+L \frac{d i_{c c}}{d t}+u_{c c}=u_{s c}
\end{array}\right.
$$

The type (1) for feed-forward decoupling transformation can be

$$
\left\{\begin{array}{l}
u_{c d}=u_{s d}-\omega L i_{q}+\left(-K_{P}-K_{I} / s\right)\left(i_{d}^{*}-i_{d}\right) \\
u_{c q}=u_{s q}+\omega L i_{d}+\left(-K_{P}-K_{I} / s\right)\left(i_{q}^{*}-i_{q}\right)
\end{array}\right.
$$

In the formula, KP 、 KI respectively proportional, integral coefficient.

\section{DC CAPACITOR VOLTAGE BALANCE CONTROL OF}

\section{ADJACENT INDUCTANCE ENERGY EQUILIBRIUM}

\section{A. Control of overall system power}

Chain STATCOM overall power control as shown in Fig .2, by separating the system active power and reactive power decoupling control, the realization of the link, the total active and reactive power control. $u_{d c}^{*}$ is the link rated voltage, $\bar{u}_{d c}$ is the average DC capacitor voltage. By adjusting the active current commands $i_{d}^{*}$ to change the uptake of active power system.

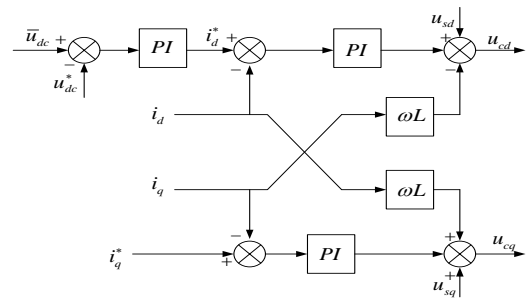

Figure 2 overall system power control

\section{B. Adjacent inductance balanced energy control and realization method thereof}

1) Adjacent inductance balanced energy control

Active power in general sufficient conditions, due to differences in the parameters of each module, if you do not use voltage balance control between modules, modules will appear over charge and discharge module, resulting in a serious imbalance between the module voltage, even cause the system can work normally.

As shown in Fig .3, this paper expounds the control thought according to the voltage balance of the three inter module. Assume that the $\mathrm{Cj}$ voltage is higher than the reference value uref, $\mathrm{Cj}-1 、 \mathrm{Cj}+1$ voltage is less than the reference value uref, by controlling the controllable switch tube $\mathrm{Kj}$, diodes $\mathrm{Dj}-1 、 \mathrm{Dj}+1$ turn-on and turn off, application of inductively as intermediate storage unit, high voltage capacitor energy transfer, can make the bias stability within the set value of each module of the DC capacitor voltage finally, the realization of DC side capacitor voltage balance. The specific steps:

- The excess energy of capacitance $C_{j}$ is first transferred to the inductance $L_{j-1} 、 L_{j+1}$, the realization method is open $K_{j}, D_{j-1}, D_{j+1}$ off.

- $\quad$ Through the inductance $L_{j-1} 、 L_{j+1}$ respectively to transfer energy to the $C_{j-1} 、 C_{j+1}$, the realization method is to turn off $K_{j}, D_{j-1}, D_{j+1}$ opened, the voltage of capacitor $C_{j-1}, C_{j+1}$ will increase.

- Repeat the previous two steps, can make each module capacitance voltage difference in a set range, so as to realize the voltage balance of the three modules.

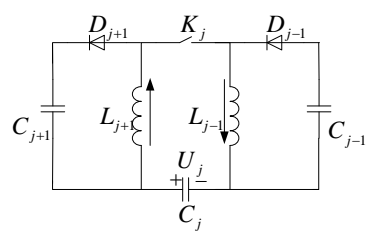

- $\quad$ Figure 3 Schematic diagram of the adjacent control inductor energy equilibrium

\section{2) realization method thereof}

In the actual system, especially in high power applications, the number of cascade module is far greater than 3 , so this paper with $\mathrm{N}$ power module design of adjacent inductance balanced energy control system. Adjacent inductance energy equilibrium control block diagram as shown in Fig .4, the control system is mainly composed of an inductor $\mathrm{L}$, a microcomputer control system, a voltage detecting unit and switch network composed of P, P 0 and 1 switch exists two kinds of logic, a logic 0 , logic switch off; 1 , switch opening, the voltage detecting unit detects the the DC capacitor voltage, comparing the DC side voltage pulses generated by the microcomputer control system, drive the corresponding voltage balance control circuit to work, so that the energy transfer from high voltage to low voltage.

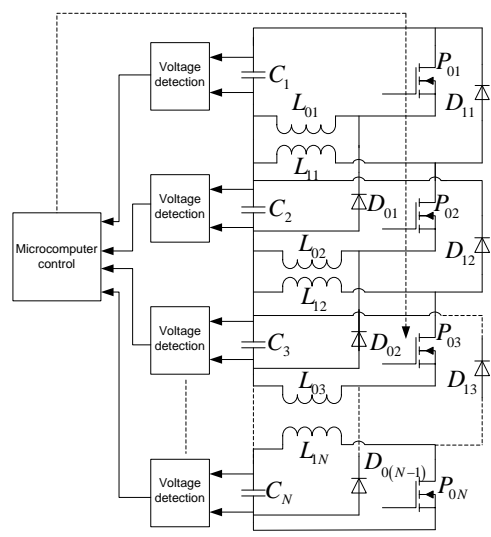

- $\quad$ Figure 4 Adjacent inductance energy equilibrium control block diagram

Process of the capacitor voltage balance is actually a constant voltage comparison process, considering the inconsistency of the capacitor voltage, microcomputer control system through the real-time detection of the voltage detecting unit voltage of each module of DC side capacitor, compare the current working cycle and the 
highest voltage capacitor $C_{\text {max }}$, the calculation of voltage difference $\Delta U$ of voltage $C_{m a x}$ and voltage reference Uref, and difference compared with the voltage reference value $\varepsilon$. When $\Delta U>\varepsilon$, driver bypass switch $P_{m a x}$ of $C_{\max }$, corresponding energy storage inductance $L_{\max }$ to absorb the excess energy of $C_{m a x}$; during the $P_{\max }$ off, $L_{\max }$ transfer energy to the adjacent DC side capacitor. When $\Delta U<\varepsilon$, it returns the control system for the next detection comparison. The above steps reciprocating operation, can realize every module of DC side capacitor voltage balance. The characteristics of this control method is the maximum probability of each module of the opening of the bypass switch is not necessarily equal, and the module of inconsistency is greater, the greater the chance to open the bypass switch, voltage balance efficiency is high, the voltage equilibrium time is smaller.

\section{THE SIMULATION AND EXPERIMENTAL}

\section{ANALYSIS}

\section{A. Simulation}

Using Matlab/Simulink to build a simulation model of a figure of 1 , simulation parameters : $u_{s}=380 \mathrm{~V}$, grid frequency $\mathrm{fs}=50 \mathrm{HZ}$, interconnection inductance $\mathrm{L}=2 \mathrm{mH}$, DC side capacitorCdc $=5000 \mu \mathrm{F}, \quad \mathrm{DC}$ capacitor of voltageudc $=190 \mathrm{~V}, \mathrm{~N}=5$.

Fig .5 (a) only the upper control, the DC capacitor voltage unbalance phenomenon is obvious, not to $191 \mathrm{~V}$ in $182 \mathrm{~V}$ respectively; Fig .5 (b) for joining the adjacent inductance balanced energy DC capacitor voltage control, can be seen that the DC capacitor voltage tends to be consistent, stable at around $190 \mathrm{~V}$. As can be seen, This control method can effectively balance the DC side capacitor voltage.

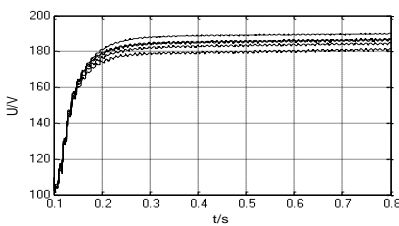

(a) Only the upper control

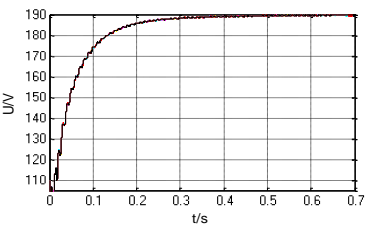

(b) Join lower balance control
Figure 5 DC capacitor voltage waveform

Fig .6 is the chain STATCOM load before and after compensation harmonic and reactive power dynamic waveform and voltage frequency spectrum. Fig .6 (a), (c) as before compensation harmonic and reactive current waveform and power grid A phase voltage spectrum, as can be seen, the input chain before STATCOM harmonic current fluctuations obviously, contains a lot of reactive power and harmonic components of the grid voltage, harmonic distortion rate THD=3.13\%; Fig .6 (b), (after D) to compensate harmonics and reactive dynamic waveform and power grid A phase voltage spectrum, into the chain of STATCOM in time, harmonic and reactive current quickly compensated, containing only the minimal harmonic and reactive current component, and the THD is reduced to $0.48 \%$. Visible, the chain STATCOM can quickly to compensate the harmonics and reactive power.
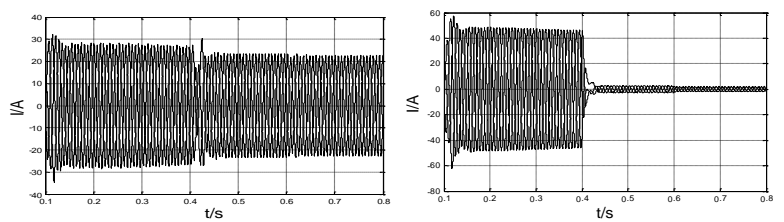

(a) Grid current before compensation (b) Grid current after compensation
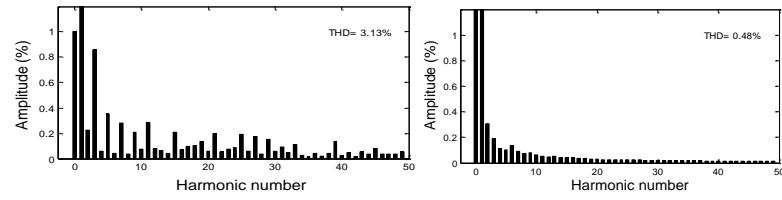

(c) Grid voltage spectrum before compensation

(d) Grid voltage spectrum after compensation

- $\quad$ Figure 6 Chain STATCOM compensating load current waveform and voltage of power grid spectrum

\section{B. Experiment}

The main circuit of chain STATCOM connected with triangles, each phase is composed of $5 \mathrm{H}$ bridge power module which are connected in series, the system voltage is $380 \mathrm{~V}$, the DC side capacitor voltage reference value $120 \mathrm{~V}$,respectively, in joining the capacitor energy transfer control and without capacitor energy transfer experiments were conducted under the control of. Fig .7 for two cases of the A phase DC side capacitor voltage waveform. From the experiment we can see, do not add balance control, A phase DC side capacitor voltage is not consistent, the highest voltage is $136 \mathrm{~V}$, the minimum voltage is $104 \mathrm{~V}$, the maximum difference reached $32 \mathrm{~V}$, output voltage total harmonic distortion rate of $\mathrm{THD}=3.74 \%$; adding balance control of each module DC side capacitor voltage difference decreases, basically the same, the highest voltage is $125 \mathrm{~V}$, the minimum voltage is $119 \mathrm{~V}$, the maximum difference is only $6 \mathrm{~V}$, output voltage total harmonic distortion rate of $\mathrm{THD}=2.42 \%$,. Experiments prove the effectiveness of the proposed method.

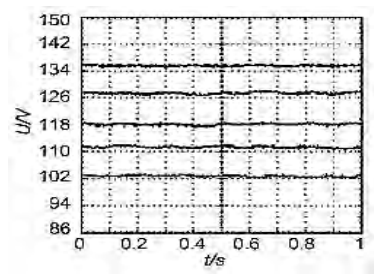

(a) Only the upper control

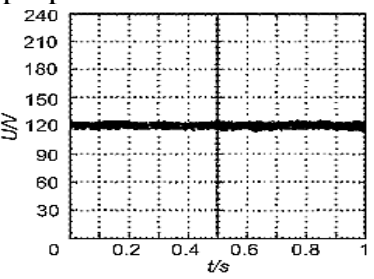

(b) Join lower balance control
-

Figure 7 Each module of the DC side capacitor voltage experimental waveforms

\section{CONCLUSION}

This paper uses the adjacent inductance energy equilibrium control method to balance the chain STATCOM DC capacitor voltage, the method has the advantages of high precision, fast speed, simple control method etc.. The simulation and experimental results show 
that: the adjacent inductance balanced energy control method can effectively solve the problem, the DC side capacitor voltage balancing effect is good, has higher application value.

\section{ACKNOWLEDGMENT}

This work was supported National Natural Science Foundation of China (51077046),Hunan Natural Science Foundation of China (14JJ2116),Key Discipline Constrution Project of Hunan Province, China (201176), and Hunan Natural Science Foundation of China (2015JJ5009).

\section{REFERENCES}

[1] Geng Juncheng, Liu Wenhua, Yu Xufeng, et al.Modeling of cascade STATCOM[J]. Proceedings of the CSEE, 2003, 23(6): 66-70.

[2] Akagi $\mathrm{H}$, Inoue $\mathrm{S}$, Yoshii $\mathrm{T}$. Control and performanceof a transformer-less cascade PWM STATCOM withstar configuration[J]. IEEE Transations on Industry Applications, 2007, 43(4): 1041-1049.

[3] Liu Wenhua, Song Qiang, Teng Letian, et al.Balancing control of DC voltage of 50Mvar STATCOM based on cascade multilevel inverters[J].Proceedings of the CSEE, 2004, 24(2): 145-150.
[4] Liu Zhao, Liu Bangyin, Duan Shanxu, et al. capacitor voltage balancing control for cascade multilevel STATCOM[J]. Proceedings of the CSEE, 2009,29(30): 7-12.

[5] Liang Yiqiao, Nwankpa C O. A new type of STATCOM based on cascading voltage-source inverters with phase shifted unipolar STATCOM[J].IEEE Transations on Industry Applications, 1999, 35(5): 1919-1927.

[6] Yidan Li, Bin Wu. A novel DC voltage detection technique in the CHB inverter based STATCOM[J].IEEE Transactions on Power Delivery, 2008, 23(3):1613-1619.

[7] Barrena J A, Marroyo L, Vidal M A R, et al. Individual voltage balancing strategy for PWM cascaded H-Bridge converter based STATCOM[J]. IEEE Trans. on Industry Electronics, 2008, 55(1) : 1512-1521.

[8]Woodhouse M L, Donoghue M W, Osbome M M. Type testing of the GTO valves for a novel STATCOM converter[C].Seventh International Conference on AC-DC Power Transmission, London, United Kingdom, 2001.

[9] Yidan Li, Bin Wu. A novel DC voltage detection technique in the CHB inverter based STATCOM[J].IEEE Transactions on Power Delivery, 2008, 23(3):1613-1619.

[10]Peng F Z, Wang Jin . A universal STATCOM with delta-connected cascade multilevel inverter[C] . Power Electronics Specialists Conference, Aachen, Germany, 2004.

[11] Wei Wenhui, Liu Wenhua, Song Qiang, et al. Research on fast dynamic control of static synchronous compensator using cascade multilevel inverter[J]. Proceedings of the CSEE, 2005, 25(3) : 23-28(in Chinese). 